\title{
ANALISIS JENIS PASIR TERHADAP KUAT TEKAN BETON
}

\author{
Surya Hadi \\ Dosen Program Studi Teknik Sipil, Fakultas Teknik, \\ Universitas Islam Al-Azhar Mataram \\ Email: hdsurya11@gmail.com
}

\begin{abstract}
ABSTRAK
Beton merupakan material bangunan yang paling banyak digunakan dalam pembanguan konstruksi, baik pada konstruksi bangunan gedung dan bangunan lainnya. Salah satu keunggulan beton yaitu ketahanan beton terhadap tekan. Kuat tekan beton sangat tergantung dari kualitas bahan-bahan penyusunnya seperti semen, agregat halus (pasir) dan agregat kasar (kerikil). Pada penilitian ini diambil jenis pasir yang berbeda yaitu pasir dari Sungai Kekeri, Sungai Dodokan dan Sungai Babak. Tujuannya adalah untuk mengatahui besar kuat tekan beton dari ketiga sungai tersebut. Penelitian dilaksanakan di Laboratorium Struktur dan Bahan Fakultas Teknik Universitas Islam Al-Azhar Mataram dan Fakutas Teknik Universitas Mataram. Bahan yang digunakan dalam penelitian ini adalah semen sebagai bahan pengikat adukan digunakan tipe merk I Tiga Roda dengan kemasan kantong isi $40 \mathrm{~kg}$. Benda uji yang digunakan untuk pengujian kuat tekan adalah berupa beton silinder berdiameter $150 \mathrm{~mm}$ dan tinggi $300 \mathrm{~mm}$. Dari hasil penelitian diperoleh nilai kuat tekan beton rata-rata setelah dikoversi pada umur beton 28 hari berturu turut Sungai Kekeri sebesar 28,16 MPa Sungai Dodokan sebesar 24,31 Mpa dan dari Sungai Babak sebesar 21,34 MPa. Dari hasil pengujian dapat dilihat bahwa pasir dengan kualitas tinggi berasal dari Sungai Kekeri kemudian Sungai Dodokan dan pasir dengan kualitas paling rendah adalah pasir dari Sungai Babak.
\end{abstract}

\section{Kata Kunci : Konversi, Konstruksi, Kuat Tekan}

\begin{abstract}
Concrete is a building material which is frequently used in the construction, whether in the construction of building and other kinds of construction. One of the benefits of using concrete is that its durability towards stress. Compressive strength of concrete really depends on the quality of the materials such as cement, fine aggregate (sand) and coarse aggregate (gravel). In this research, the samples of sand were taken from different river namely Kekeri River, Dodokan River and Babak River. It aimed to investigate the compressive strength of concrete from those three rivers. This research was conducted at the Laboratory of Structure and Material Faculty of Engineering Unizar and Faculty of Engineering Universitas Mataram. The materials used in this research as follows: cement as the mortar binder used for brand type I Tiga Roda with packing weight 40kg. The object used for the testing of compressive strength was $150 \mathrm{~mm}$ diameter cylindrical concrete with heigh 300mm. From the findings, the average value of compressive strength of concrete after being converted in the age 28 days as follows: Kekeri River was 28,16 MPa, Dodokan River was 24,31 MPa and Babak River was 21,34 MPa. From
\end{abstract}


the testing, it was seen that the sands with high quality consecutively came from Kekeri River, Dodokan River, and the lowest quality came from Babak River.

\section{Keywords: Conversion, Construction, Compressive Strength}

\section{PENDAHULUAN}

Beton merupakan salah satu bahan bangunan yang banyak digunakan dalam bidang konstruksi. Beton dibuat dari campuran semen portland, agregat, air dan atau bahan tambah. Beberapa kelebihan beton sebagai material dari konstruksi adalah tahan api, ekonomis, perawatan yang mudah dan murah, mudah didapatkan. Kekurangankekurangan yang ada, seperti kuat tarik yang rendah dan getas sering menimbulkan kerugian yang tidak diharapkan, sehingga harus mendapat perhatian dan menjadi alasan untuk memilih bahan lain sebagai bahan untuk struktur.

Dalam membuat beton ada beberapa hal yang yang harus dipertimbangkan antara lain jenis agregat (agregat halus ataupun agregat kasar), gradasi agregat, kehausan agregat, tempat pengambilan agregat, jenis semen serta cara pembuatannya dan lain sebagainya. Agregat untuk pencampuran beton biasanya terdiri dari pasir halus dan pasir kasar. Pasir halus untuk beton dapat berupa pasir alam sebagai hasil desintegrasi alami dari hasil batu-batuan atau berupa buatan yang di hasilkan oleh alat pemecah batu. Menurut SNI (2002) pasir halus adalah butiran yang berukuran maksimum $5 \mathrm{~mm}$ dan minimum berukuran 0,063 $\mathrm{mm}$ kandungan pasir dalam campuran beton biasanya sangat tinggi.komposisi pasir tersebut berkisar 60\%-70\% dari berat campuran beton. Walau fungsinya hanya sebagai pengisi, tetapi karena komposisinya yang cukup besar maka pasir ini pun menjadi penting dalam pembutan beton. Sifat pasir yang paling berpengaruh terhadap kekuatan beton adalah kekerasan butiran-butiran pasir dan ukuran maksimumnya dari campuran beton yang sesuai dengan yang diisyaratkan.

Kabupten Lombok Barat memiliki kekayaan alam yang melimpah, salah satunya adalah bahan atau material yang dapat dijadikan sebagai bahan yang menjadi agregat sebagai bahan pengisi campuran beton. Material tersebut dapat menjadi alternatif material yang bisa dijangkau oleh masyarakat sekitar daerah tersebut. Agregat-agregat yang akan di gunakan baik agregat halus dan agregat kasar berasal dari sungai yang ada di kawasan Kabupaten Lombok Barat. Dengan menggunakan berbagai macam agregat yang nantinya akan di variasikan untuk campuran beton di harapkan akan mendapatkan suatu variasi campuran yang akan menghasilkan suatu mutu beton yang optimal dan nantinya bisa di gunakan sebagai alternatif untuk pekerjaan beton lainnya. Pada penelitian ini, penulis akan mencoba beberapa daerah asal pengambilan pasir sebagai bahan campuran beton. Tujuan yang ingin diketahui dari penelitian ini adalah untuk mengetahui pengaruh dari sumber pengambilan pasir terhadap kuat tekan beton.

\section{TINJAUAN PUSTAKA}

Menurut SNI 2847-2013, beton didefinisikan sebagai campuran antara semen portland atau semen hidraulik lainnya, agregat halus, agregat kasar dan air dengan atau tanpa bahan campuran tambahan (admixture). Bahan tambah ialah bahan selain 
unsur pokok beton (air, semen dan agregat), yang ditambahkan pada adukan beton, sebelum atau selama pengadukan beton. Tujuannya ialah mengubah satu atau lebih sifat-sifat beton sewaktu masih dalam keadaan segar atau setelah mengeras, misalnya memperlambat waktu pengikatan, mempercepat pengerasan, menambah encer adukan, menambah daktilitas (mengurangi sifat getas), mengurangi retakretak pengerasan, mengurangi panas hidrasi, menambah kekedapan, menambah keawetan dan sebagainya (Tjokrodimuljo, 2007).

Ditinjau dari berat isi beton, beton normal adalah beton yang mempunyai berat isi $2200-2500 \mathrm{~kg} / \mathrm{m} 3$ yang menggunakan agregat alam yang pecah atau tanpa di pecah yang tidak menggunakan bahan tambahan (SNI 03-2847-2002). Kuat tekan beton normal berkisar antara 28-60 MPa pada umur beton 28 hari. Beton terdiri dari \pm 15 $\%$ semen, $\pm 8 \%$ air, $\pm 3 \%$ udara, selebihnya pasir dan kerikil. Campuran tersebut setelah mengeras mempunyai sifat yang berbeda-beda, tergantung pada cara pembuatannya. Perbandingan campuran, cara pencampuran, cara mengangkut, cara mencetak, cara memadatkan, dan sebagainya akan mempengaruhi sifat-sifat beton (Wuryati dan Candra, 2001).

\section{Bahan Penyusun Beton Semen}

Semen merupakan salah satu unsur pengikat pembentuk beton jika bercapur air. Semen portland adalah semen hidrolis yang di hasilkan dengan cara menghaluskan klinker yang terutama terduri dari silikat- silikat kalsium yang bersifat hidrolis dengan gips sebagai bahan tambahan (Tjokrodimuljo, 1996).

Penyusun semen terdiri dari bahan-bahan yang mengandung kapur, silikat, alumina dan oksida besi.Ktiga bahan dasartadi di campur dan di bakar dengan suhu 1.550 C dan menjadi klinker kemudian didinginkan dan dihaluskan seperti bubuk. Biasanya ditambahkan dengan gips sebagai bahan pengontrol pada waktu pengikat. Senyawa utama semen portlan dapat dilihat.

Bila semen terkena air maka $\mathrm{C}_{3} \mathrm{~S}$ segera terhidrasi dan menghasilkan panas dan berpengaruh terhadap pengerasan semen.sebaliknya $\mathrm{C}_{3} \mathrm{~A}$ berhidrasi sangat cepat ,memberikan kekuatan setelah 24 jam.Unsur $\mathrm{C}_{4} \mathrm{AF}$ kurang begitu besarpengaruhnya terhadap kekerasan semen atau beton. Semen porlands di bagi menjadi lima jenis (Tjokrodimuljo, 1996), sebagai berikut:

Jenis I : Semen untuk pengguna umum, tidak memerlukan persaratan khusus.

Jenis II : Semen untuk bahan tahan terhadap sulfat dan mempunyai panas hidrasi sedang.

Jenis III : Semen untuk beton dengan kekuatan awal yang ringan.

Jenis V : Semen untuk beton yang sangat tahan terhadap sulfat.

Menurut Tjokrodimulyo (1990), sifat fisik semen yang penting yaitu adalah halusan butir,waktu ikatan dan panas hidrasi.

\section{Agregat}

Agregat adalah butiran mineral alami yang berfungsi sebagai bahan pengisi dalam campuran mortal atau beton. Agregat ini kira-kira menempati sebanyak $70 \%$ 
volume beton. Dalam Tjokrodimulijo (1996), sebaiknya agregat untuk bahan bangunan dipilih yang memenuhi persyaratan sebagai berikut : (1) Butir-butir tajam, kuat dan bersudut, (2) tidak mengandung tanah atau kotoran lain yang lewat ayakan $0,075 \mathrm{~mm}$, pada agregat halus jumlah kandungan kotoran ini harus tidak lebih dari 5\% untuk beton $10 \mathrm{Mpa}$, (3) harus tidak mengandung garam yang menghisap air dari udara, (4) harus yang benar-benar tidak mengandung zat organic, (5) harus mempunyai variasi besar butir (gradasi) yang baik sehingga rongganya sedikit, (6) tahan lama, tidak hancur atau berubah karena cuaca, (7) untuk beton dengan tingkat keawetan yang tinggi, agregat harus mempunyai tingkat reaktif yang negative terhadap alkali, (8) Untuk agregat kasar, tidak boleh mengandung butiran-butiran yang pipih dan panjang lebih dari $20 \%$ berat keseluruhan.

Dalam menunjukkan ukuran kehalusan dan kekasaran butir-butir agregat, biasanya digunakan indeks modulus halus butir $(\mathrm{mh})$ yang didefinisikan sebagai jumlah persen komulatif dari butir-butir agregat yang tertinggal di atas suatu set ayakan dan kemudian dibagi seratus (Tjokrodimuljo, 1996). Makin besar nilai modulus halus butir menunjukkan bahwa makin tinggi proporsi agregat yang berdiameter besar. Pasir mempunyai modulus halus butir antar 1,5 sampai 3,8. Sedangkan kerikil mempunyai m.h.b antara 5 dan 8 .

\section{Agregat Kasar}

Agregat kasar adalah kerikil alami dari batuan atau berupa batu pecah yang diperoleh dari industry pemecah batu dan mempunyai ukuran butir antara 5-40 mm. Sifat agregat kasar mempengaruhi kekuatan akhir beton keras dan daya tahannya terhadap kekuatan beton. Agregat kasar ini harus bersih dari bahan-bahan organic dan harus mempunyai ikatan yang baik dengan gel semen. Jenis agregat kasar yang umum adalah batu pecah alami, kerikil alami, agregat kasar batuan dan agregat kasar buatan. Permukaan yang halus pada kerikil dan kasar pada batu pecah berpengaruh pada lekatan dan besar tegangan saat retak-retak beton mulai terbentuk.Besar ukuran maksimum agregat mempengaruhi kuat tekan beton.

\section{Agregat Halus}

Agregat halus adalah pasir alam atau pasir yang dihasilkan oleh industry pemecah batu dan mempunyai ukuran butiran sebesar 5,0 $\mathrm{mm}$. agregat halus yang baik harus bebas bahan organic, lempung atau bahan-bahan lain yang dapat merusak campuran beton serta mempunyai tekstur yang tajam dan keras tidak dapat dihancurkan oleh jari dan tidak mudah aus atau pecah.

Dalam Mulyono (2005), dikatakan bahwa pasir yang digunakan dalam campuran beton jika dilihat dari sumbernya dapat berasal dari sungai ataupun dari galian tambang (quarry). Agregat yang berasal dari tanah galian, yaitu tanah yang dibuka lapisan penutupnya (pre-streping), biasanya berbentuk tajam, bersudut, berpori, dan bebas dari kandungan garam. Pada kasus tertentu, agregat yang terletak pada lapisan yang paling atas harus dicuci terlebih dahulu sebelum digunakan. Pasir kasar alami biasanya dapat memenuhi syarat gradasi zona 1 dan British Standard (B.S), tetapi mineral halusnya yang berukuran lebih kecil dari 0,3 mm tidak cukup banyak. Pasir yang masuk Zona II dan III dapat juga ditemukan dalam pasir alami, 
tetapi biasanya banyak mengandung silt dan tanah liat. Batas gradasi untuk agregat halus dibagi menjadi empat zone menurut British Standar yaitu zone 1 merupakan pasir kasar, zone 2 merupakan pasir agak kasar, zone 3 merupakan pasir agak halus dan zone 4 merupakan daerah pasir halus.

\begin{abstract}
Air
Menurut Murdock dan Brook (1999), di dalam campuran beton, air mempunyai dua buah fungsi, yang pertama, untuk memungkinkan reaksi kimia yang menyebabkan pengikatan dan berlangsungnya pengerasan dan kedua sebagai pelican campuran kerikil, pasir dan semen agar memudahkan percetakan. Air diperlukan pada pembuatan beton agar terjadi reaksi kimiawi dengan semen untuk membasahi agregat dan untuk melumas campuran agar mudah pengerjaannya (Nawy, 1998).
\end{abstract}

Air diperlukan pada pembuatan beton agar terjadi reaksi kimiawi dengan semen untuk membasahi agregat dan untuk melumas campuran agar mudah pengerjaannya (Nawy, 1998). Pada umumnya air minum dapat dipakai untuk mencampur beton. Jumlah air yang diperlukan untuk proses hidrasi hanya kira-kira $25 \%$ dari berat semennya. Penambahan jumlah air akan mengurangi kekuatan setelah mengeras (Tjokrodimuljo), 1996). Namun demikian kelebihan air yang diperlukan dalam proses hidrasi pada umumnya memang diperlukan pada pembuatan beton agar adukan dapat dicampur dengan baik, diangkut dengan mudah dan dapat dicetak tanpa rongga yang besar. Selain itu apabila air terlalu banyak maka kelebihan air itu secara bersama-sama dengan semen akan bergerak kepermukaan adukan beton segar yang baru saja dituang sehingga menyebabkan bleeding yang akan menjadi buih dan berbentuk lapisan tipis yang dikenal dengan thin membrane (selaput tipis). Selaput tipis ini akan mengurangi lekatan antar lapisan beton dan menjadi bidang sambung yang lemah. Apabila ada kebocoran pada cetakan maka air bersama-sama semen keluar. Air yang mengandung senyawa-senyawa yang berbahaya, yang tercemar garam, minyak, gula atau bahan-bahan kimia lain, bila dipakai untuk campuran beton akan sangat menurunkan kekuatannya dan dapat juga mengubah sifat-sifat semen.

\title{
Faktor Air Semen
}

Faktor air semen adalah perbandingan antara air dan berat semen pada campuran adukan beton. Hukum ini memberikan arti bahwa beton yang dipadatkan sempurna dengan agregat yang baik pada kadar semen tertentu, kekuatannya tergantung pada besarnya faktor ini semen (fas). Faktor air semen yang rendah menyebabkan air di antara bagian-bagian semen sedikit, sehingga jarak antara butiran-butiran semen menjadi pendek, akibatnya massa semen menunjukkan lebih berkaitan, karenanya kekuatan awal lebih dipengaruhi dan akhirnya batuan semen mencapai kepadatan tinggi. Semen dapat mengikat air sekitar $40 \%$ dari besarnya, dengan kata lain air sebaanyak 0,4 kali berat semen telah cukup untuk membuat semen berhidrasi. Kepadatan adukan beton juga sangat mempengaruhi kuat tekan beton setelah mengeras. Adanya pori-pori udara sebesar 5\% dapat mengurangi kuat tekan beton sampai 35\% dan pori-pori udara sebanyak $10 \%$ dapat mengurangi kekuatan beton sampai 60\% (Tjokrodimuljo, 1996). 


\section{METODE PENELITIAN}

Penelitian dilaksanakan di Laboratorium Struktur dan Bahan Fakultas Teknik Universitas Islam Al-Azhar Mataram dan Fakutas Teknik Universitas Mataram. Bahan-bahan yang digunakan dalam penelitian ini adalah sebagai adalah semen sebagai bahan pengikat adukan digunakan tipe merk I Tiga Roda dengan kemasan kantong isi 40kg. Agregat halus (pasir) yang digunakan diambil dari tiga sungai yaitu dari Sungai Dodokan, Sungai Babak dan Sungai Kekeri Kabupaten Lombok Barat. Sebelum dipakai sebagai salah satu unsur penyusun beton serat, terlebih dahulu digunakan pengujian untuk mengetahui gradasi, berat jenis, berat satuan agregat dan kandungan lumpur pada pasir tersebut. Sedangkan agregat kasarnya diambil dari kekeri. Untuk air yang digunakan adalah air bersih yang berasal dari jaringan air PDAM mataram. Benda uji yang digunakan untuk pengujian kuat tekan adalah berupa beton silinder berdiameter $150 \mathrm{~mm}$ dan tinggi $300 \mathrm{~mm}$. Proporsi campurn berdasarkan SK-SNI-T-15-1990-03 tentang "Tata Cara Pembuatan Rencana Campuran Beton Normal". Jumlah benda uji masing-masing sungai pada penelitian 9 benda uji .

\section{HASIL DAN PEMBAHASAN}

\section{Hasil Pengujian Material}

Pemeriksaan bahan penyusun beton yang dilaksanakan sebelum dilakukan penelitian meliputi pemeriksaan berat satuan agregat, pemeriksaan berat jenis agregat, pemeriksaan gradasi agregat, pemeriksaan kandungan lumpur agregat halus dan pemeriksaan ketahanan aus agregat kasar. Hasil pemeriksaan bahan penyusun beton Sungai Kekeri dapat dilihat pada Tabel 1. Hasil pemeriksaan bahan penyusun beton Sungai Dodokan dapat dilihat pada Tabel 2. Hasil pemeriksaan bahan penyusun beton Sungai Babak dapat dilihat pada Tabel 3.

Hasil pemeriksaan pasir menghasilkan data masing-masing untuk Sungai Kekeri dengan berat satuan lepas rata-rata $1,216 \mathrm{gr} / \mathrm{cm}^{3}$ dan berat satuan padat $1,550 \mathrm{gr} / \mathrm{cm}^{3}$ , untuk dari Sungai Dodokan dengan berat satuan lepas rata-rata sebesar 1,337 $\mathrm{gr} / \mathrm{cm}^{3}$ dan berat satuan padat rata-rata sebesar $1,546 \mathrm{gr} / \mathrm{cm}^{3}$, dan Sungai Babak dengan berat satuan lepas $0,996 \mathrm{gr} / \mathrm{cm}^{3}$ dan berat satuan padat rata-rata 1,353 $\mathrm{gr} / \mathrm{cm}^{3}$. Berat satuan termasuk dalam jenis agregat normal yang memiliki berat satuan antara 1,2-1,6 gr/ $\mathrm{cm}^{3}$ (Tjokrodimuljo,2007). Sedangkan untuk Sungai Babak tidak termasuk dalam jenis agregat normal karena berat satuannya kurang dari berat satuan agregat normal.

Sedangkan pemeriksaan untuk sungai Kekeri didapatkan berat jenis dalam kondisi kering rata-rata sebesar 2,54 gr/ $\mathrm{cm}^{3}$ dan berat jenis dalam kondisi SSD sebesar 2,24 $\mathrm{gr} / \mathrm{cm}^{3}$ serta penyerapan air sebesar $9,55 \%$. Untuk sungai dodokan berat jenis dalam kondisi kerinng rata-rata sebesar $2,68 \mathrm{gr} / \mathrm{cm}^{3}$, berat jenis dalam kondisi SSD sebesar 2,36 $\mathrm{gr} / \mathrm{cm}^{3}$ dan penyerapan air sebesar 8,92 \%, dan untuk Sungai Babak didapatkan berat jenis dalam kondisi kering rata-rata sebesar 2,49 $\mathrm{gr} / \mathrm{cm}^{3}$, berat jenis dalam kondisi SSD sebesar 2,08 $\mathrm{gr} / \mathrm{cm}^{3}$ dan penyerapan air sebesar 8,92\%. Hasil ini menunjukkan bahwa pasir dan kerikil yang digunakan termasuk jenis agregat normal yang memiliki berat jenis antara 2,5-2,7 (Tjokrodimuljo, 2007). 
Untuk modulus kehalusan untuk sungai kekeri ,dodokan dan sungai babak masing masing 2,1 sumgai kekeri, 1,6 sungai dodokan dan sungai babak 1,3. Berdasarkan Tjokrodimuljo, 2007 persyaratan modulus kehalusan butiran sebesar 1,5-3,8.

Hasil pemeriksaan kandungan lumpur agregat halus menunjukkan masing-masing pasir yang digunakan memiliki kandungan lumpur untuk, untuk Sungai Kekeri sebesar 4,09, Sungai Dodokan sebesar 2,58\% dan untuk Sungai Babakan sebesar $3,04 \%$ dari berat agregat. Persyaratan yang harus dipenuhi oleh agregat halus sebagai bahan penyusun beton adalah kandungan lumpur pasir tidak boleh lebih dari 5\% dari berat agregat (Tjokrodimuljo), 2007).

Tabel 1. Hasil Pemeriksaan Bahan Penyusun Beton Sungai Kekeri

\begin{tabular}{|l|l|l|l|}
\hline No & \multicolumn{2}{|l|}{ Jenis Pemeriksaan } & Agregat Halus (Pasir) \\
\hline 1 & \multicolumn{2}{|l|}{ Berat Satuan Agregat } & \\
\hline & A $\quad$ Berat satuan agregat lepas $\left(\mathrm{kg} / \mathrm{m}^{3}\right)$ & 1216 \\
\hline & B & Berat satuan agregat padat $\left(\mathrm{kg} / \mathrm{m}^{3}\right)$ & 1550 \\
\hline 2 & Berat Jenis Agregat & \\
\hline & A $\quad$ Berat jenis kondisi SSD & 2,24 \\
\hline & B & Berat jenis kondisi kering & 2,54 \\
\hline & C & Penyerapan air $(\%)$ & 9,56 \\
\hline 3 & Gradasi Agregat (MHB) & 2,1 \\
\hline 4 & Kandungan Lumpur $(\%)$ & 4,09 \\
\hline 5 & Ketahanan Aus $(\%)$ & \\
\hline & A & 100 putaran & - \\
\hline & b & 500 putaran & - \\
\hline 6 & \multicolumn{2}{|l}{ Kadar Air $(\%)$} & 9,55 \\
\hline
\end{tabular}

Tabel 2. Hasil Pemeriksaan Bahan Penyusun Beton Sungai Dodokan

\begin{tabular}{|c|c|c|c|}
\hline No & \multicolumn{2}{|c|}{ Jenis Pemeriksaan } & Agregat Halus (Pasir) \\
\hline 1 & \multicolumn{2}{|c|}{ Berat Satuan Agregat } & \\
\hline & $\mathrm{a}$ & $\begin{array}{l}\text { Berat satuan agregat lepas } \\
\left(\mathrm{kg} / \mathrm{m}^{3}\right)\end{array}$ & 1337 \\
\hline & $\mathrm{b}$ & $\begin{array}{l}\text { Berat satuan agregat padat } \\
\left(\mathrm{kg} / \mathrm{m}^{3}\right)\end{array}$ & 1546 \\
\hline \multirow[t]{4}{*}{2} & \multicolumn{2}{|c|}{ Berat Jenis Agregat } & \\
\hline & $\mathrm{a}$ & Berat jenis kondisi SSD & 2,36 \\
\hline & $\mathrm{b}$ & Berat jenis kondisi kering & 2,68 \\
\hline & $\mathrm{c}$ & Penyerapan air (\%) & 8,92 \\
\hline 3 & \multicolumn{2}{|c|}{ Gradasi Agregat (MHB) } & 1,6 \\
\hline 4 & \multicolumn{2}{|c|}{ Kandungan Lumpur (\%) } & 2,58 \\
\hline 5 & \multicolumn{2}{|c|}{ Ketahanan Aus (\%) } & \\
\hline
\end{tabular}




\begin{tabular}{|l|l|l|l|} 
& $\mathrm{a}$ & 100 putaran & - \\
\hline & $\mathrm{b}$ & 500 putaran & - \\
\hline 6 & Kadar Air $(\%)$ & 8,92 \\
\hline
\end{tabular}

Tabel 3. Hasil Pemeriksaan Bahan Penyusun Beton Sungai Babak

\begin{tabular}{|l|l|l|l|}
\hline No & Jenis Pemeriksaan & Agregat Halus (Pasir) \\
\hline 1 & Berat Satuan Agregat & \\
\hline & a & $\begin{array}{l}\text { Berat satuan agregat lepas } \\
\left(\mathrm{kg} / \mathrm{m}^{3}\right)\end{array}$ & 0,996 \\
\hline & $\mathrm{b}$ & $\begin{array}{l}\text { Berat satuan agregat padat } \\
\left(\mathrm{kg} / \mathrm{m}^{3}\right)\end{array}$ & 1,353 \\
\hline 2 & Berat Jenis Agregat & \\
\hline & a & Berat jenis kondisi SSD & 2,08 \\
\hline & $\mathrm{b}$ & Berat jenis kondisi kering & 2,49 \\
\hline & $\mathrm{c}$ & Penyerapan air $(\%)$ & 8,92 \\
\hline 3 & Gradasi Agregat (MHB) & 1,3 \\
\hline 4 & Kandungan Lumpur (\%) & 3,04 \\
\hline 5 & Ketahanan Aus (\%) & \\
\hline & a 100 putaran & - \\
\hline & b 500 putaran & 17,24 \\
\hline 6 & Kadar Air $(\%)$ & - \\
\hline
\end{tabular}

\section{Pengujian Kuat Tekan Beton}

Pelaksanaan pengujian kuat tekan beton dengan benda uji silinder $15 \mathrm{~cm}$ x $30 \mathrm{~cm}$ dilakukan setelah benda uji beton berumur 28 hari.Pada pengujian kuat tekan data yang didapatkan adalah beban maksimum yang mengakibatkan benda uji mengalami keruntuhan.Kuat tekan beton kemudian dihitung menggunakan Persamaan berikut.

$$
\mathrm{f}^{\prime} \mathrm{c}=\frac{P}{A}
$$

dengan:

$$
\begin{aligned}
& \mathrm{f}^{\prime} \mathrm{c}=\text { Kuat tekan beton }(\mathrm{MPa}) \\
& \mathrm{P}=\text { Beban maksimum }(\mathrm{N}) \\
& \mathrm{A}=\text { Luas bidang tekan }\left(\mathrm{mm}^{2}\right)
\end{aligned}
$$

\section{Hasil pengujian kuat tekan}

Hasil pengujian kuat tekan beton dengan menggunakan campuran pasir Sungai Kekeri dapat dilihat pada Tabel 4. Hasil pengujian kuat tekan beton dengan menggunakan campuran pasir Sungai Dodokan dapat dilihat pada Tabel 5. Hasil 
pengujian kuat tekan beton dengan menggunakan campuran pasir Sungai Babak dapat dilihat pada Tabel 6 .

Tabel 4. Tabel Hasil Pengujian Kuat Tekan Beton Jenis Pasir Sungai Kekeri

\begin{tabular}{|c|c|c|c|c|c|c|c|c|c|}
\hline \multirow{2}{*}{ No } & \multirow{2}{*}{$\begin{array}{l}\text { Kode } \\
\text { Benda } \\
\text { Uji }\end{array}$} & \multicolumn{2}{|c|}{ Dimensi } & \multirow{2}{*}{$\begin{array}{l}\text { Luas } \\
\mathbf{m m}^{2}\end{array}$} & \multirow{2}{*}{$\begin{array}{l}\text { Umur } \\
\text { uji } \\
\text { beton } \\
\text { (hari) }\end{array}$} & \multicolumn{2}{|c|}{ P МАK. } & \multirow{2}{*}{$\begin{array}{l}\text { Kuat } \\
\text { Tekan } \\
\text { pada } \\
\text { umur } \\
\text { uji } \\
\text { Silinder } \\
\text { Mpa }\end{array}$} & \multirow{2}{*}{$\begin{array}{l}\begin{array}{l}\text { Hasil uji } \\
\text { kuat } \\
\text { tekan }\end{array} \\
\text { Konversi } \\
\text { umur 28 } \\
\text { hari MPa }\end{array}$} \\
\hline & & $\begin{array}{l}\mathbf{L} \\
(\mathbf{m m})\end{array}$ & $\begin{array}{l}\text { D } \\
(\mathbf{m m})\end{array}$ & & & $\mathbf{k N}$ & $\mathbf{N}$ & & \\
\hline (1) & $(2)$ & \multicolumn{2}{|l|}{ (3) } & $(6)$ & (7) & & $(8)$ & (9) & $(10)$ \\
\hline 1 & $\begin{array}{l}\text { Smp. } \\
1\end{array}$ & 300 & 150 & 17662,5 & 7 & 300 & 300000 & 16,99 & 26,14 \\
\hline 2 & $\begin{array}{l}\text { Smp. } \\
2\end{array}$ & 300 & 150 & 17662,5 & 7 & 280 & 280000 & 15,85 & 24,38 \\
\hline 3 & $\begin{array}{l}\text { Smp. } \\
3\end{array}$ & 300 & 150 & 17662,5 & 7 & 270 & 270000 & 15,29 & 23,52 \\
\hline \multicolumn{8}{|c|}{ Kuat tekan rata-rata } & 18,31 & 24,68 \\
\hline
\end{tabular}

Dari Tabel 4 didapatkan hasil pengujian kuat tekan dari pasir Sungai kekeri untuk sampel (1) yaitu 16,99 MPa, untuk sampel (2) 15,85 MPa dan untuk sampel (3) 15,29 $\mathrm{MPa}$ dengan rata-rata 18,31 $\mathrm{MPa}$, diperkirakan hasil uji untuk kuat tekan silinder beton pada umur 28 hari dengan faktor koreksi 0,65 kuat tekan rata-rata sebesar 24,68 Mpa. Dari Tabel 5, Sungai Dodokan dihasilkan untuk sampel (1) yaitu 18,12Mpa, untuk sampel (2) $18,68 \mathrm{MPa}$ dan untuk sampel (3) $18,12 \mathrm{MPa}$ dengan rata-rata $18,04 \mathrm{MPa}$, diperkirakan hasil untuk ujiuntuk kuat tekan silinder beton pada umur 28 hari dengan kuat tekan rata-rata yaitu 28,16 Mpa.. Sedangkan Tabel 6, untuk pengujian dengan jenis pasir Sungai Babak sampel 1 yaitu, 14,15 MPa, untuk sampel (2) 14,44 MPa dan untuk sampel (3) 13,02 MPa dengan ratarata $13,87 \mathrm{MPa}$, diperkirakan hasil uji untuk kuat tekan silinder beton pada umur 28 hari dengan kuat tekan rata-rata sebesar 21,34 MPa.

Tabel 5. Tabel Hasil Pengujian Kuat Tekan Beton Jenis Pasir Sungai Dodokan

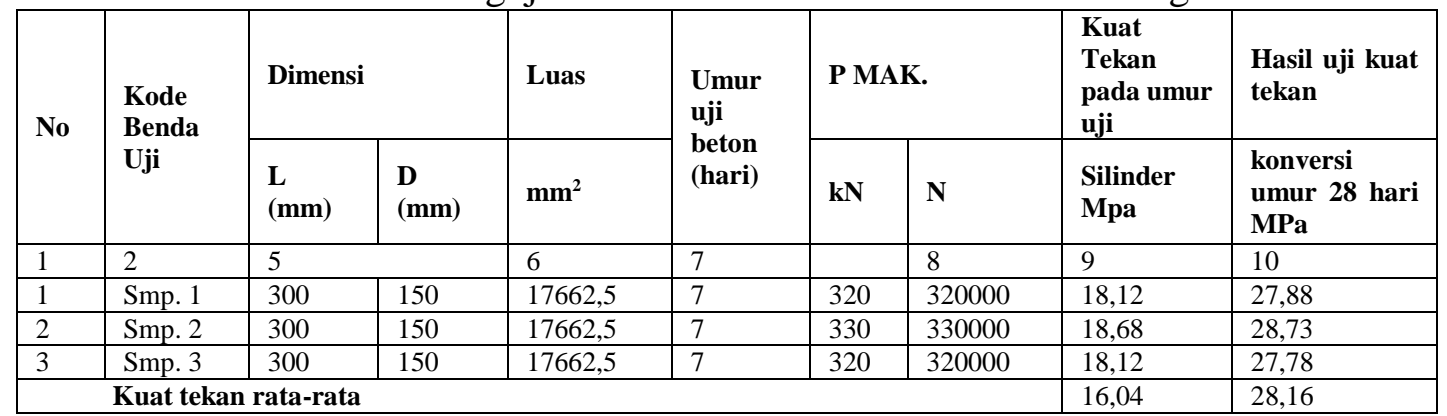

Tabel 6.Tabel Hasil Pengujian Kuat Tekan Beton Jenis Pasir Sungai Babak 
JURNAL KACAPURI

JURNAL KEILMUAN TEKNIK SIPIL

Volume 3 Nomor 2 Edisi Desember 2020

\begin{tabular}{|c|c|c|c|c|c|c|c|c|c|}
\hline \multirow{2}{*}{ No } & \multirow{2}{*}{$\begin{array}{l}\text { Kode } \\
\text { Benda } \\
\text { Uji }\end{array}$} & \multicolumn{2}{|c|}{ Dimensi } & \multirow{2}{*}{$\begin{array}{l}\text { Luas } \\
\text { Mm }\end{array}$} & \multirow{2}{*}{$\begin{array}{l}\text { Umur } \\
\text { uji } \\
\text { beton } \\
\text { (hari) }\end{array}$} & \multicolumn{2}{|c|}{ P MAK. } & \multirow{2}{*}{$\begin{array}{l}\begin{array}{l}\text { Kuat } \\
\text { Tekan } \\
\text { pada } \\
\text { umur uji }\end{array} \\
\begin{array}{l}\text { Silinder } \\
\text { Mpa }\end{array}\end{array}$} & \multirow{2}{*}{$\begin{array}{l}\begin{array}{l}\text { Perkiraan } \\
\text { kuat tekan }\end{array} \\
\begin{array}{l}\text { konversi } \\
\text { umur } 28 \text { har } \\
\text { MPa }\end{array}\end{array}$} \\
\hline & & $\begin{array}{l}\mathbf{L} \\
(\mathbf{m m})\end{array}$ & $\begin{array}{l}\text { D } \\
(\mathbf{m m})\end{array}$ & & & $\mathbf{k N}$ & $\mathbf{N}$ & & \\
\hline 1 & 2 & \multicolumn{2}{|l|}{5} & 6 & 7 & & 8 & 9 & 10 \\
\hline 1 & Smp. 1 & 300 & 150 & 17662,5 & 7 & 320 & 250000 & 14,15 & 21,77 \\
\hline 2 & Smp. 2 & 300 & 150 & 17662,5 & 7 & 255 & 255000 & 14,44 & 22,22 \\
\hline 3 & Smp. 3 & 300 & 150 & 17662,5 & 7 & 230 & 230000 & 13,02 & 20,03 \\
\hline \multicolumn{8}{|c|}{ Kuat tekan rata-rata } & 13,87 & 21,34 \\
\hline
\end{tabular}

\section{PENUTUP}

Dari hasil penelitian dan pembahasan, maka dapat diambil kesimpulan sebagai berikut:

1. Dari tiga jenis pasir yang berbeda dalam penelitian ini menghasilkan hasil pengujian kuat tekan setelah diadakan konversi utntuk umur 28 hari masing masing sebagai berikut : Pasir dari Sungai Kekeri kuat tekan beton sebesar 24,68 Mpa, Pasir dari Sungai Dodokan sebesar 28,16MPa. Sedangkan Pasir dari Sungai Babak sebesar 21,34 MPa.

2. Kuat tekan dengan jenis pasir yang berasal dari Sungai Dodokan memiliki nilai kuat tekan paling tinggi sebesar sebesar 28,16 MPa.

Dari hasil penelitian yang telah dilaksanakan, disarankan utk penelitiaan selanjutya dengan mengambil pasir dari daerah lain selain yang diatas dan jumlah benda uji yang lebih banyak

\section{DAFTAR PUSTAKA}

1. Astanto, T.B. 2001. Konstruksi Beton Bertulang. Yokyakarta: Kanisius.

2. Amri, S. 2005. Teknologi Beton A-Z. Jakarta: Yayasan John Hi-Tech Idetama.

3. Mulyono, T.. Teknologi Beton. Yohyakarta: C.V Andi Offset.

4. Murdock, L.J. dan Brook, K.M. 1991. Bahan dan Praktek Beton, Edisi Keempat, Terjemahan oleh Stephanus Hindarko. Jakarta: Erlangga.

5. Nawy. E.G. 1998. Structure Beton Bertulang. New Jersey: Univ.Rutgers.

6. Tjokrodimuljo, K. 1996,. Teknologi Beton. Yogyakarta: Nafiri. 